I Universidade de São Paulo (USP), Departamento de Antropologia,

\title{
EQUILÍBRIO E RISCO: A VITALIDADE DE GUERRA E PAZ1
}

Araújo, Ricardo Benzaquen de. (20I7). Guerra y paz:

Casa grande y senzala y la obra de Gilberto Freyre en los años I930.

Traducción: Ada Solari.

Bernal: Universidad Nacional de Quilmes Editorial.

Como apresentar esse volume magro, de autor desconhecido em língua espanhola, cujo título cita o clássico de Tolstói? Fiel ao espírito de síntese do livro, eu diria que ele reúne um dos grandes escritores brasileiros, Gilberto Freyre, e o seu maior intérprete, Ricardo Benzaquen de Araújo. Esse encontro feliz converte-o em referência obrigatória não apenas pelo que ensina sobre o antropólogo, sociólogo e historiador pernambucano, mas também por seu estilo crítico. Estamos diante de um ensaio exemplar do ponto de vista da forma e do feitio da interpretação.

Originalmente tese de doutorado em antropologia social defendida no Museu Nacional da Universidade Federal do Rio de Janeiro, em I994, Guerra e paz subverte o formato convencio- nal dos trabalhos acadêmicos e as leituras disponíveis sobre a obra de Gilberto Freyre (I900-I987). É certo que quando a primeira edição do livro vem à luz, Freyre já tinha o seu lugar assegurado como um dos grandes intérpretes do Brasil, figurando como autor de Casa-grande \& senzala (I933), obra que, ao lado de Raízes do Brasil (I936), de Sérgio Buarque de Holanda, e de Formação econômica do Brasil (I942), de Caio Prado Jr., invertem as trilhas correntes do ensaísmo nacional, sobretudo por escapar das explicações raciais, e racistas, que vaticinavam a inviabilidade da nação mestiça, com o auxílio de novas inspirações teóricas, fundamentalmente, o marxismo (Caio Prado Jr.); a sociologia alemã (Sérgio Buarque) e a antropologia cultural norte-americana (Gilberto Freyre). 
Freyre, porém, desenha percurso particular em relação aos seus companheiros de geração. Sua formação dá-se longe dos cursos de direito, pelos quais passa parte de seus contemporâneos (Sérgio Buarque e Caio Prado incluídos), e afastada, em seus primeiros tempos, da Europa, rota obrigatória para a intelectualidade brasileira até então. O curso de ciências sociais e os Estados Unidos o receberão, primeiro na Universidade de Baylor e em seguida na Universidade de Columbia, quando realiza o mestrado Social life in Brazil in the middle of the Igth, publicado na Hispanic American Historical Review, em I922. A formação acadêmica feita fora do país, entretanto, não impede a manutenção de vínculos permanentes com a cidade natal, que as crônicas regulares publicadas no Diário de Pernambu$\mathrm{CO}^{2}$ alimentam; crônicas nas quais ele exercita um olhar comparado sobre cidades e arquitetura; comportamentos e vida social; arte e política; e que preparam a sua volta à capital do estado de Pernambuco em I923, quando passa a liderar o chamado movimento regionalista pernambucano. ${ }^{3}$

A experiência norte-americana, marcada pelos cursos e leituras comparadas sobre a experiência escravista no Brasil e nos EUA e pela antropologia de Franz Boas; o giro europeu realizado em I922 e I923 (Inglaterra, Alemanha, França, Bélgica, Espanha e Portugal) e a movimentação cultural do Recife na década de I920 fornecem o solo onde germinará Casagrande \& senzala, obra escrita durante um período de exílio, quando Freyre deixa o país acompanhando o então governador de Pernambuco, destituído pela Revolução de I930, Estácio Coimbra, de quem era chefe de gabinete.

É sobre Casa-grande \& senzala e sobre a obra de Gilberto Freyre dos anos I930 que se debruça o ensaio de Ricardo Benzaquen de Araújo; o seu horizonte é, portanto, a cena modernista brasileira em duas de suas vertentes díspares, a paulista e a pernambucana, assim como as relações mais amplas entre as ciências sociais e os modernismos, que o timbre híbrido do ensaio de Freyre auxilia a elucidar. Se isso é verdade, a análise não privilegia os panoramas histórico-culturais, optando pelo exame minucioso do livro de I933 e das demais produções de Freyre do período, ${ }^{4}$ que fornecem as chaves de leitura para Casa-grande \& senzala, ainda hoje a obra mais conhecida de Gilberto Freyre, e para a compreensão das teses, do estilo e método do autor.

Guerra e paz encontra-se organizado em duas grandes partes e uma conclusão curta. Na primeira, "A Rússia americana”, o autor realiza uma leitura detida da obra de estreia de Freyre; na segunda, "Arsênico e alfazema”, volta-se para outros de seus livros publicados em 30, utilizados para obtermos uma "visão mais ampla e matizada" da reflexão de Gilberto no período em questão, como também para uma "visão mais fina e detalhada de seu grande livro de estreia". Destaco 
"visão ampla e matizada", "fina e detalhada", termos várias vezes repetidos, e com a ajuda dos quais o autor define o seu comentário à obra: comentário "o mais completo e meticuloso que fui capaz de fazer, em torno daqueles que me pareceram ser os argumentos substantivos de Casa-grande \& senzala", diz ele. A abertura da análise na direção de outros escritos de Freyre, longe de tentar resolver problemas ou contradições postas pela obra primeira, faz emergirem novos pontos de vista, a produção de Gilberto Freyre dos anos I930 revelando-se um conjunto heterogêneo, repleto de ambiguidades e paradoxos que o analista põe a nu.

Não são poucos os achados de Guerra e paz em relação a Casa-grande \& senzala. Em primeiro lugar, o livro ensina que ao invés da substituição do conceito de raça pelo conceito de cultura, lugar-comum da crítica até então, nota-se a convivência das duas noções na obra, tornadas compatíveis pela mediação da categoria "meio físico". Isso só é possível, diz Benzaquen, porque Gilberto Freyre trabalha com uma noção neolamarckiana de raça, fortemente ancorada na ideia de adaptação. Em segundo lugar, a análise qualifica a noção de mestiçagem que figura no livro de 1933 e se mostra aí como justaposição de traços e qualidades (jamais como "mistura" ou "fusão"), revelando, para surpresa de muitos, que o mestiço que sai dessas páginas é o português, ser híbrido por excelência, "equilibrado entre antagonismos". A concepção de "equilíbrio de antagonismos", utilizada para definir o por- tuguês, expande-se na direção da interpretação do brasileiro e da própria sociedade brasileira, sociedade que se mostra na análise freyriana "híbrida, sincrética e quase polifônica", avessa a qualquer tipo de totalização estabilizadora.

Finalmente, e ao contrário do que enfatizavam as leituras disponíveis sobre o escritor brasileiro, Guerra e paz detecta a combinação das imagens do paraíso e do inferno no período colonial brasileiro, a tolerância e a flexibilidade convivendo, nesse contexto, com a violência e o terror. A ideia de trópico, por seu turno, que irá adquirir relevo em obras futuras, apareceria já no livro de 1933 associada aos excessos, responsáveis tanto pela criação de zonas de confraternização entre negros e brancos (o sexo) quanto pela destruição e pela morte (a sífilis). A casa-grande colonial apresenta-se, assim, envolta em atmosfera marcada pela hybris, mas que não exclui a disciplina e o planejamento, evidentes nos métodos bárbaros utilizados pelos senhores de engenho em relação à mão de obra escrava, de modo a obter máximos rendimentos.

A noção de antagonismos em equilíbrio, chave para a compreensão do português e das relações entre casagrande e senzala, mostra-se fundamental para o delineamento da perspectiva analítica de Freyre, exímia em aproximar antagonismos e que, por isso mesmo, projeta uma visão de cultura e de sociedade como unidades precárias e sincréticas, marcadas pela convivência tensa, mas sempre equilibrada, de opostos. Tal visa- 
da foi forjada a partir de diálogos com certas noções e tradições, apresentadas de modo preciso e econômico ao longo de Guerra e paz, o que confere ritmo particular à interpretação: ela nos convida a sair do texto, a fim de conhecermos as referências e os modelos do autor (como os debates políticos e intelectuais sobre a raça; as teorias disponíveis sobre a escravidão; o franciscanismo e o puritanismo), voltando em seguida a ele.

Se a segunda parte do volume, dedicada a Sobrados e mucambos e a outros textos da mesma década, quer funcionar como um contexto de leitura da obra de estreia de Gilberto Freyre, ela abriga as mais belas e engenhosas interpretações de Ricardo Benzaquen de Araújo. Sem almejar reaver o conjunto dos argumentos apresentados, chamo atenção apenas para as páginas notáveis do segmento "Cinzas que queimam", no qual ele se detém no modo como o intérprete pernambucano concebe o processo de reeuropeização do Brasil que tem lugar século XIX, e que encontra tradução em um progressivo embotamento do mundo, que o empalidecimento das cores evidencia. "A hybris que condicionava a antiga casa-grande se expressava, por conseguinte, nessa impressionante profusão de cores vivas e berrantes, profusão que foi 'empalidecendo ao contato com a nova Europa, foi se acinzentando' [...]" (I36).

O evidente tom crítico de Freyre em relação ao processo civilizatório brasileiro examinado em Sobrados e mucambos não deve ser tomado como simples recusa à importação de ele- mentos adventícios, adverte o analista; tal julgamento associa-se antes à "tendência à estetização da existência" que tal processo estimula, tendência que se revela, no plano privado, na obsessão com as aparências e com o artificialismo, perceptíveis na nova forma que os jardins domésticos vão exibir (os "canteirinhos geométricos" se insinuando em meio às "irregularidades" e "imprevistos" reinantes nos jardins das casas brasileiras até então) e, na vida pública, pelo privilégio concedido à retórica, às frases ornamentadas e arredondadas, que o ensino religioso, sobretudo o jesuítico, auxiliou a difundir no Brasil oitocentista.

Mas, cautela leitor; não nos precipitemos na construção de fossos entre as sociedades colonial e imperial brasileiras, assinala Benzaquen. Afinal, a retórica não guardaria, por meio da oratória ornamental e excessiva, a memória da hybris presente em Casa-grande \& senzala? Caminhando e aprofundando essa linha interpretativa, o analista indica que os bacharéis oriundos dos sobrados urbanos, afeitos ao brilho fácil e superficial da retórica, mostram-se personagens efeminados, ciosos da ornamentação dos seus discursos e de seus corpos.

Outra das façanhas interpretativas de Guerra e paz localiza-se também nessa segunda parte, precisamente em seu trecho final, "A arca de Noé", dedicado à investigação das proclamadas imprecisões da reflexão de Freyre. Sem pretender denunciar lacunas ou falhas, certas inconsis- 
tências das formulações freyrianas são tomadas como vias de acesso à forma de sua interpretação e aproveitadas, ainda, para introduzir as demais produções dos anos 1930 na análise (os Guias de cidades brasileiras, Mucambos do Nordeste e Nordeste, por exemplo). A consideração desses outros escritos leva ao vislumbre de uma segunda acepção de mestiçagem (dessa vez, sinônima de fusão) e à compreensão do modo como o universo popular se faz presente na reflexão do autor; universo popular valorizado por sua associação à humildade e à fraternidade e, no limite, aos valores franciscanos. Com isso, e mais uma vez contra os lugares comuns da crítica, que tendia a sublinhar a perspectiva aristocrática do escritor, Ricardo Benzaquen assinala a convivência de dois pontos de vista distintos na obra de Gilberto Freyre dos anos 30: um associado à casa-grande, e outro ao mocambo. E ao mocambo se ligam também as mulheres, valorizadas como alternativas ao universo comedido, europeu e excludente dos sobrados.

No segmento conclusivo, Casa-grande \& senzala é reintroduzida na análise com a ajuda da oralidade, face oposta à retórica tratada na segunda parte do volume. As páginas finais são eloquentes em relação ao método crítico de Ricardo Benzaquen, que elas apresentam em uma espécie de drágea concentrada. O mote da reflexão nesse trecho são as discussões sobre o estilo do livro de I933, no qual uma prosa de tipo oral, marcada pela imprecisão e inacabamento, terminaria por conferir a ele valor de obra literária. Recorrendo a textos pouco comentados de Freyre para fornecer novos enquadramentos à compreensão de sua perspectiva, o autor argumenta que o reconhecimento do valor literário da obra, unanimidade entre os comentadores, não deve nublar a vocação acadêmica e científica do estudo, tampouco a orientação pública e a concepção de política que a obra contém e que esses outros textos auxiliam a evidenciar.

Sem discordar dos argumentos dos críticos, Benzaquen busca ampliá-los, estabelecendo um diálogo respeitoso com os demais intérpretes do escritor, mesmo quando não concorda com suas teses. Procedimento exemplar de sua personalidade crítica: pensar com o outro, contra o outro e contra si mesmo, tal é o jogo reflexivo e argumentativo sobre o qual Guerra e paz é montado, o que lhe confere enorme vitalidade, o leitor sendo provocado a participar das conversas e a (re)formular os seus próprios pontos de vista.

O caráter sucinto de Guerra e paz é o seu traço mais evidente. "Síntese econômica e brilhante", diria Francisco Falcon sobre o livro anterior de Ricardo, Totalitarismo e revolução. O integralismo de Plínio Salgado (I988), ${ }^{5}$ palavras que certamente valem para o estudo sobre Gilberto Freyre. Outras das observações feitas por Falcon nesse prefácio poderiam, aliás, funcionar como comentários a Guerra e paz, por exemplo quando ele confessa a dificuldade de definir o trabalho sobre o integralismo brasileiro "segundo as regras acadêmicas vigentes". Tomando de empréstimo as pa- 
lavras do historiador carioca, poderíamos perguntar: como definir Guerra e paz segundo as convenções acadêmicas de nosso tempo?

O livro traz as marcas da formação sui generis de seu artífice. Bacharel em história pela Universidade $\mathrm{Ca}$ tólica do Rio de Janeiro (PUC-Rio), em I974, e tendo concluído um mestrado (I980) e um doutorado (I993) em antropologia no Museu Nacional, em período de grande efervescência da instituição, Ricardo Benzaquen iniciou-se no mundo profissional como professor de história antiga e medieval na PUC-Rio e como pesquisador do Centro de Pesquisa e Documentação de História Contemporânea do Brasil (CPDOC) da Fundação Getulio Vargas, onde se dedicou ao estudo do pensamento social brasileiro. Ao lado disso, manteve diálogo intenso com os sociólogos no interior do Instituto Universitário de Pesquisas do Rio de Janeiro (Iuperj) da Universidade Cândido Mendes, onde lecionou entre I987 e 20I2, e com os críticos literários, especialmente com Luís Costa Lima (que escreve o prefácio à primeira edição de Guerra e paz ${ }^{6}$ ), e com Hans Ulrich Gumbrecht, da Universidade de Stanford. Os círculos interdisciplinares frequentados desde o início da carreira - entre os quais os comitês editoriais de algumas das mais importantes revistas científicas brasileiras e o grupo do "Pensamento Social no Brasil", da Associação Nacional de Pós-Graduação em Ciências Sociais (Anpocs), além dos incontáveis eventos e bancas de teses, das mais diferentes áreas - são índices expressivos do seu trânsito entre campos disciplinares diversos. Lembremos ainda a sua atuação para o impulso do Programa de Pós-Graduação em História Social da Cultura da PUC-Rio, do qual foi docente, único no país em função de sua proximidade com as humanidades e com as artes, e de sua forte inclinação teórica.

Essas experiências deixam marcas no ensaio erudito sobre o escritor brasileiro, que possui encadeamento de conversa com o leitor, a quem ele se dirige ao longo da narrativa. Não é difícil notar na forma do texto escrito as respirações tão particulares do estilo oral de Ricardo, conhecido de seus alunos, tocados e transformados pelas aulas do professor apaixonado, como eles não se cansam de dizer. Tampouco passam despercebidos os contrastes que ele mobiliza no título desse e de outros trabalhos (guerra e paz, o linho e a seda, raios e trovões, entre outros7), que evocam os contrários com os quais Freyre batiza os volumes de sua trilogia sobre a formação e decadência do patriarcalismo no Brasil: Casa-grande \& senzala, Sobrados e mucambos, e Ordem e progresso. ${ }^{8}$ Tanto o escritor como o seu intérprete recorrem à antítese como forma reflexiva fundamental, convertendo a convivência de opostos na razão de ser de suas análises.

Ainda sobre os títulos escolhidos por Ricardo Benzaquen para os seus ensaios, é possível lembrar as sucessivas alusões feitas às artes: à pintura (Ronda noturna, de Rembrandt); ao cinema (Chuvas de verão, de Cacá Diegues e À sombra do vulcão, de John 
Houston) e à literatura, a que Guerra e paz faz referência. ${ }^{9}$ Tais eleições, longe de anedóticas ou decorativas, deixam ver a maneira como as artes figuram em suas análises, como molas propulsoras do conhecimento.

Sem querer forçar continuidades entre trabalhos separados no tempo, parece plausível afirmar que Guerra e paz coroa procedimentos anteriormente exercitados. A exegese de certo vocabulário conceitual, buscando nuances e matizes de modo a alargar a compreensão do pensamento em tela é um traço saliente do perfil crítico de Ricardo Benzaquen, que se mostra de forma clara nos livros de I988 e I994. No escrito sobre Plínio Salgado tratava-se de examinar a doutrina integralista distinguindo noções frequentemente confundidas: totalitarismo, fascismo, conservadorismo e autoritarismo. No ensaio sobre Gilberto Freyre, por sua vez, o intérprete volta a colocar o foco de sua atenção sobre noções caras ao escritor - raça, cultura e mestiçagem, por exemplo -, contribuindo para expandir a compreensão de suas teses e o entendimento do próprio modernismo brasileiro, que se mostra plural e heterogêneo nas duas análises realizadas, seja pela consideração da tendência nacionalista do movimento (que Plínio Salgado exemplifica), seja pela leitura do regionalismo, "a seu modo modernista", defendido por Gilberto Freyre.

Recuando ainda mais no tempo, encontramos o mesmo tipo de exercício exegético meticuloso na análise da categoria "amor" em William Shake- speare - "Romeu e Julieta e a origem do Estado" (I977) -, realizado com o então colega de doutorado no Museu Nacional Eduardo Viveiros de Castro, ${ }^{\mathrm{I}}$ ou na observação das categorias mobilizadas pelos jogadores de futebol falando sobre a profissão (abatimento, autocrítica, confiança, humildade etc.), esforço empreendido em Os gênios da pelota, dissertação de mestrado inédita. ${ }^{\text {II }}$ Guerra e paz indica também a retomada de temas e questões, especialmente o empenho de seu autor em projetar novas luzes sobre o nosso modernismo, reinterpretado de outra perspectiva, quer dizer, daquela que contraria os caminhos estabelecidos. Aliás, contornar as convenções e os cânones, intelectual e politicamente falando, parece ter sido uma das opções de Ricardo ao eleger sistematicamente autores malvistos e mal lidos, em função de seus partidos ideológicos: além de Plínio Salgado e Gilberto Freyre, Gustavo Barroso e Miguel Reale, sobre os quais também escreveu. ${ }^{\mathrm{I} 2}$

O próprio Ricardo reconhece o esforço em nadar contra a corrente ideológica do momento quando se volta para a obra de Freyre na década de I980. Em suas palavras: "Gilberto Freyre era considerado um autor intelectualmente desprezível. Isso muito em função do seu próprio vínculo com posições mais à direita. Ele tinha uma conexão forte com o governo salazarista e depois foi um dos poucos intelectuais que apoiaram de maneira explícita o regime instituído pelo golpe de 64. Ao mesmo tempo eu já estava lidando com comentadores nacionais e estrangeiros que chamavam a aten- 
ção para o fato de que, independentemente dos vínculos políticos de Gilberto, a sua obra, sobretudo Casa- grande \& senzala, Sobrados e mucambos e Nordeste, era seminal. Basta lembrar os prefácios estrangeiros à obra de Gilberto. Lucien Febvre vai prefaciar a edição francesa; Fernand Braudel assina o prefácio da edição italiana". ${ }^{\text {3ㅜ } \mathrm{O}}$ estudioso lança-se assim à difícil tarefa de enfrentar analiticamente um autor rechaçado no Brasil em função das posições políticas de direita assumidas na maturidade e que, a despeito disso, é recebido com entusiasmo pela intelectualidade francesa de esquerda. $^{\text {I4 }}$

Guerra e paz pode ser lido, assim, como resultado de um percurso anterior, errático em função dos deslocamentos do autor entre instituições e campos de conhecimentos, mas coerente do ponto de vista da fidelidade a rotas interpretativas, a certos autores (Simmel é um deles) e ao empenho em nos afastar das trilhas consagradas, por meio da escolha de autores deixados de escanteio; da análise meticulosa, "atenta às ambiguidades e aos paradoxos"; da "avaliação cautelosa" que evita "precipitações classificatórias" e que almeja contribuir para "sínteses mais abrangentes, complexas e matizadas" - os termos encontram-se nas páginas iniciais de Guerra e paz, que cito de forma livre.

A partir do escrutínio das ideias, Ricardo Benzaquen de Araújo logra realizar uma costura fina entre a forma do texto freyriano, o conteúdo de suas teses e o perfil do autor. No estilo oral do ensaio de Freyre, assim como nas discussões sobre as particularidades da língua brasileira (das quais participou com outros intelectuais de seu tempo), o estudioso surpreende a dupla personalidade do escritor, ligada à dimensão popular da linguagem e da sociedade, como também à ascendência aristocrática, que Freyre reivindica em mais de uma ocasião e que os seus comentadores enfatizam. Somos apresentados, assim, a uma identidade pessoal e intelectual formada por tradições opostas, que se misturam à matéria narrada. Tal espelhamento entre criador e criatura irá conferir "autenticidade" ao texto, o escritor colocando-se no interior da experiência tratada e no centro da narrativa. "Nesses termos, não acredito que seja descabido sugerir que a forma de Gilberto argumentar, 'usando a mesma língua que todos falam' e identificando-se tão fortemente com seus antepassados, acabe por produzir a sensação de que os objetos que estuda permanecem vivos e influentes através do seu relato, quer dizer, vivos porque influentes na confecção do seu texto. Casa-grande \& senzala deixa, então, de ser apenas um livro para transformar-se em uma espécie de casa-grande em miniatura, em uma voz longínqua mas genuína, legítima e metonímica representante daquela experiência que ele próprio analisava, enquanto o nosso autor se converte, até certo ponto, em personagem de si mesmo, como se escrevesse não só um ensaio histórico-sociológico mas também as suas mais íntimas memórias" (189). 
Pelo exame da oralidade e da autenticidade no segmento final de Guerra e paz, Benzaquen chama a atenção para o modernismo dissonante de Freyre (frequentemente colocado nas antípodas do moderno, como uma alternativa conservadora a ele), que encontra expressão nas suas análises do Brasil e da cultura brasileira, apoiadas na pesquisa científica de corte moderno e em uma forma ensaística talhada pelo inacabamento; inacabamento que atinge voltagem máxima pelo recurso às antinomias e pela defesa de pontos de vista contrários.

Longe de conclusivo, o autor encerra o livro com sugestões e "impressões", como ele prefere, que se abrem na direção de novas indagações, o que nos leva a perguntar: não seria o inacabamento também um traço do ensaio de Ricardo Benza- quen? Uma frase de Totalitarismo e revolução parece reafirmar a hipótese: "Não acredito muito em análises definitivas, particularmente nas elaboradas dentro da república das letras, pelo simples fato dela ser uma república" (p. III).

Em contexto brasileiro, o livro de Ricardo Benzaquen de Araújo não apenas reorientou os rumos da recepção da obra de Gilberto Freyre, como estabeleceu um padrão de excelência para os estudos sobre o pensamento social. Traduzido agora para o espanhol, ele seguramente desenhará outros percursos interpretativos em função de novos horizontes de debate e reflexão. Mas ao deslocar-se, transformando-se por entre rotas e paragens inéditas, mantém intacta a sua força vital: um perfil crítico raro, equilibrado entre a cautela analítica e o risco interpretativo.

Recebida em 28/07/2017 | Aprovada em 30/07/2017

Fernanda Arêas Peixoto é professora do Departamento de Antropologia da Universidade de São Paulo (USP) e pesquisadora do CNPq. É autora de Diálogos brasileiros: uma análise da obra de Roger Bastide (2000) e A viagem como vocação (20I5). 


\section{NOTAS}

I Este texto foi publicado em espanhol como prefácio à edição argentina do livro de Ricardo Benzaquen, objeto dessa resenha.

2 Crônicas reunidas em Tempo de aprendiz: artigos publicados em jornais na adolescência e na primeira mocidade do autor (I9I8-I926). Organização de José Antônio Gonçalves de Mello. 2 v. Brasília: Ibrasa/Instituto Nacional do Livro. 1979.

3 Esse movimento reuniu intelectuais de distintas procedências: artistas, jornalistas, escritores, sociólogos, geógrafos, políticos, médicos etc. Entre suas realizações estão: o Centro Regionalista do Nordeste (I924), o Livro do Nordeste (edição comemorativa do Diário de Pernambuco, de I925), o Io Congresso Regionalista do Nordeste (I926) e a Revista do Norte (I923-I926). Entre seus expoentes encontram-se os pintores Cícero Dias (1907-2003) e Lula Cardoso Ayres (I9Io-I987), e o escritor José Lins do Rego (I90II957).

4 São elas: Guia prático, histórico e sentimental do Recife (I934); Artigos de jornal (1935), Sobrados e mucambos (1936), Mucambos do Nordeste (I937), Nordeste (I937), Açúcar (I939) e Olinda, segundo guia prático, histórico e sentimental de cidade brasileira (I939). A bibliografia completa de Gilberto Freyre, assim como uma cronologia de sua produção e atuação podem ser consultadas na edição crítica de Casa-grande \& senzala, a cargo de Guillermo Giucci, Enrique Larreta e Edson Nery da Fonseca, Nanterre, Coleção Archivos, 2002.

5 Cf. prefácio assinado pelo historiador brasileiro Francisco José Calazans Falcon (I933) ao volume Totalitarismo e revolução: o integralismo de Plínio Salgado, Rio de Janeiro, Jorge Zahar, I988. Plínio Salgado (I895-I975) foi político e escritor brasileiro, fundador da Ação Integralista Brasileira, criada em I932, movimento político de direita, simpático ao fascismo.

6 A primeira edição da obra é de 1994, e a segunda de 2005, ambas a cargo da Editora 34. Em I995, o livro recebeu o Prêmio Jabuti, da Câmara Brasileira do Livro, uma das mais tradicionais premiações no país.

7 "O linho e seda. Notas sobre o catolicismo e a tradição inglesa em Minha formação, de Joaquim Nabuco" In: Ange- 
la Alonso \& Kenneth D. Jackson (orgs.). Joaquim Nabuco na República. São Paulo: Hucitec, 2012; "Raios e trovões. Plasticidade, excesso e modernidade na obra de Gilberto Freyre In: João Cézar Castro Rocha (org.). Nenhum Brasil existe. Pequena enciclopédia. Rio de Janeiro: Topbooks/Uerj, 2003.

8 O volume Ordem e progresso, dedicado à transição da Monarquia para a República, embora concebido ao lado dos demais, vem a público bem mais tarde, em I957. Do conjunto, faria parte também Jazigos e covas rasas, dedicado às atitudes diante da morte no Brasil, nunca realizado.

9 Cf. "Ronda noturna - narrativa, crítica e verdade em Capistrano de Abreu", Estudos históricos, I/I, I988; "Chuvas de verão" In: Lilia Schwarcz e André Botelho (orgs.). Um enigma chamado Brasil. São Paulo: Companhia das Letras, 2009; “À sombra do vulcão". In: João Cézar Castro Rocha (org.). Erich Auerbach, colóquio. Rio de Janeiro: Uerj, I994.

Io O ensaio "Romeu e Julieta e a origem do Estado" foi publicado em Velho, Otávio (org.). Arte e sociedade. Rio de Janeiro: Zahar, I977. Eduardo Viveiros de Castro (I95I), antropólogo e professor do Museu Nacional do Rio de Janeiro, é autor, entre outros, de A inconstância da alma selvagem (2002) e Métaphysiques cannibales (2009).

I I Os gênios da pelota, um estudo do futebol como profissão. Dissertação de mestrado, Museu Nacional/UFRJ, I980.

I 2 Gustavo Barroso (I888-I957) foi um dos líderes e ideólogos da Ação Integralista Brasileira, movimento ao qual aderiu também o jurista Miguel Reale (I910-2006).

I3 Entrevista a Rodrigo Elias e Cláudia Bojunga. Revista de História.com.br, disponível em <http://www.revistadehistoria.com.br/secao/entrevista/ricardo-benzaquen $>$. Acesso em I ago. 2016.

I4 Lembremos que é Roger Bastide o tradutor de Casa-grande e senzala ao francês, obra editada em I952 pela Gallimard na coleção La croix du sud, dirigida por Roger Callois, com o título Maîtres et esclaves. 